\title{
Community Hospital Experience of Surgical Times and Outcomes in Patients Undergoing Cesarean Deliveries for Non-Reassuring Fetal Tracing: A Retrospective Cohort
}

\author{
Helen Yuan1, Alexander G. Shilkrut', Hae-Young Kim², Arpit Gupta1, Hannah Sampath1, \\ Kavitha Ram1, Gladys Lee-Hwang1, Michael Girshin ${ }^{1 *}$ \\ ${ }^{1}$ Departments of Anesthesiology Metropolitan Hospital Center, New York, USA \\ ${ }^{2}$ Department of Public Health, New York Medical College, Valhalla, NY, USA \\ Email: *mgirshin@gmail.com
}

How to cite this paper: Yuan, H., Shilkrut, A.G., Kim, H.-Y., Gupta, A., Sampath, H., Ram, K., Lee-Hwang, G. and Girshin, M. (2019) Community Hospital Experience of Surgical times and Outcomes in Patients Undergoing Cesarean Deliveries for NonReassuring Fetal Tracing: A Retrospective Cohort. Open Journal of Anesthesiology, 9 , 203-211.

https://doi.org/10.4236/ojanes.2019.911020

Received: October 10, 2019

Accepted: November 12, 2019

Published: November 15, 2019

Copyright $\odot 2019$ by author(s) and Scientific Research Publishing Inc. This work is licensed under the Creative Commons Attribution International License (CC BY 4.0).

http://creativecommons.org/licenses/by/4.0/ (c) (i) Open Access

\begin{abstract}
Background: Current guidelines recommend regional anesthesia versus general as a method of choice for women undergoing cesarean deliveries (CS). However, little is known about the surgical times in the operating room and a choice of anesthesia for cesarean deliveries. Objective: This study was designed to compare times from the arrival to the OR to the delivery of the fetus between regional and general anesthesia along with maternal and fetal outcomes, for patients undergoing cesarean sections for non-reassuring fetal tracing. Study Design: Records were reviewed for patients who underwent cesarean delivery for non-reassuring fetal heart rate tracing from February 2012 to May 2018. A total of 190 charts were selected. Seven patients who received epidural or spinal anesthesia and then converted to general anesthesia (GA) were excluded. The primary outcomes were: 1) entering the operating room to skin incision ( $\mathrm{min}) ; 2$ ) the time from entering the operating room to delivery of the fetus ( $\mathrm{min}$ ). These times were compared among the patients who underwent epidural, spinal and general anesthesia. The secondary criteria included time from skin incision to delivery of the fetus ( $\mathrm{min}$ ), estimated blood loss (ml), Apgars scores, Arterial/venous cord pH, NICU admissions and fetal complications. ANOVA or Kruskal-Wallis Test was used for the continuous variable and Fisher's exact test was used for the categorical variable to test the differences between groups. Logistic regression model was used for the binary outcomes after adjusting for age, BMI and number of prior laparotomies. Results: Infants in the GA group were delivered significantly faster when compared to epidural and spinal group separately with a P-value of 0.001 . The mean time from arrival to OR to delivery of the newborn in GA
\end{abstract}


group was 12.7 minutes, compared to 27 minutes in epidural group and 32.7 minutes in the spinal group. Time intervals from time in the OR to incision and time from incision to delivery of the fetus were also calculated and were significantly shorter in the GA group when compared to spinal and epidural groups, $\mathrm{P}<0.001$. The estimated blood loss $(\mathrm{EBL})$ was similar between these three groups. Both arterial and venous umbilical cord mean $\mathrm{PH}$ were comparable in GA, spinal and epidural groups. Potential complications of GA include $36 \%$ of newborns had an Apgar score of less than 7 at 1 minute in GA group when compared to $15 \%$ of newborns in the epidural group, and $22 \%$ of newborns in the spinal group, which was not statistically significant. When comparing the NICU admission between the groups: $77 \%$ of newborns delivered under GA required NICU admission, 54\% of the newborns delivered via epidural anesthesia were admitted versus $50 \%$ of newborns delivered via spinal anesthesia. Conclusion: The induction of general anesthesia for emergency cesarean section resulted in shorter times to delivery compared to spinal and epidural. General anesthesia was associated with lower, albeit not statistically significant Apgar scores and higher NICU admissions, and had similar cord gases compared to neuraxial anesthesia group.

\section{Keywords}

Surgical, Patients, Non-Reassuring Fetal Tracing, Cesarean Deliveries, Regional Anesthesia versus General

\section{Introduction}

When an urgent cesarean delivery is indicated for a non-reassuring fetal heart rate tracing, the choice of anesthetic technique can be very important, especially because the time to delivery of the fetus is critical. The options of anesthesia for cesarean delivery include either general or neuraxial anesthesia, such as spinal, combined spinal-epidural, or epidural anesthesia. Additionally, the mode of anesthetic technique is influenced by the maternal and fetal status, comorbidities, expected duration and difficulty of the procedure, as well as whether the patient has an epidural catheter in situ.

Practice guidelines recommend regional anesthesia over general anesthesia for most cesarean deliveries [1]. In the United States and Canada, neuraxial anesthesia is the preferred technique and used for greater than 95 percent of cesarean deliveries [2]. In non-urgent cases, the advantages of neuraxial anesthesia include the avoidance of airway instrumentation, minimizing systemic medication and transfer to the fetus, allowing the mother to be awake for the birth, and delivery of neuraxial opioids for postoperative analgesia. However, during emergency cesarean deliveries where shorter intervals may potentially result in improved neonatal outcomes [3], the ideal mode of anesthesia is unclear, and general anesthesia continues to be used. While studies comparing the time taken to achieve adequate surgical anesthesia are limited, one study reported that achiev- 
ing the onset of spinal anesthesia is slower than general anesthesia induction time for emergency cesarean sections [4].

While achieving general anesthesia is generally thought to be faster than regional anesthesia, the actual amount of time saved is poorly described in the literature, and physicians often make empiric choices in emergency situations.

The purpose of this study is to review the records of patients who underwent spinal, epidural, or general anesthesia for urgent cesarean delivery for nonreassuring fetal heart rate tracing and compare the surgical and anesthetic times and delivery of the fetus with different modalities of anesthesia, as well as maternal and fetal outcomes.

\section{Methods}

This retrospective study was approved by the Institutional Review Boards (IRB) of New York Medical College and Health + Hospitals and was conducted at Metropolitan Hospital Center. Records were reviewed for patients who underwent cesarean delivery for non-reassuring fetal heart rate tracing from February 2012 to May 2018. A total of 190 charts were selected, and 7 patients who received epidural or spinal anesthesia and then converted to general anesthesia were excluded.

The data was collected through the review of medical records and scanned anesthesia records in Electronic Health Record System (QuadraMed). The patients were grouped into those that received epidural $(n=112)$, spinal $(n=50)$ and general $(\mathrm{n}=21)$ anesthesia. There were 184 babies born from 183 patients, as one patient had twin gestation. Patient variables, such as maternal age, gestational age at delivery, BMI, number of prior laparotomies and fetal weight, were extracted from the medical records. The primary outcomes included the time from entering the operating room to delivery of the infant (min), time from entering the operating room to skin incision ( $\mathrm{min}$ ), and time from skin incision to delivery of the infant ( $\mathrm{min}$ ). These times were compared among patients who underwent epidural, spinal versus general anesthesia. The secondary outcomes were estimated blood loss (ml), Apgar scores, Arterial/venous cord pH, NICU admissions and fetal complications.

ACOG recommends that labor epidural be placed on demand, in the first stage of labor [5]. For those patients where the indications are urgent, but not life threatening, and those who do not have epidural catheter in place, most providers will choose the spinal block as the main part of the anesthetic. Commonly neuraxial anesthetics will include an amide (Bupivacaine hyperbaric) with an addition of opioids (Fentanyl) and Duramorph (for postoperative pain control). The optimal dosages of the neuraxial blocks are outside the scope of this manuscript.

Continuous variables were summarized as means and standard deviations (SD). For variables that were not normally distributed, median and interquartile ranges were used. Categorical variables were summarized as percentages. ANOVA or Kruskal-Wallis Test was used for the continuous variable and Fisher's Exact Test was used for the categorical variable to test the differences between groups. 
The primary outcomes, EBL, arterial cord $\mathrm{PH}$ and venous cord $\mathrm{PH}$ were considered as the continuous outcomes. Apgar score ( $<7$ vs. $\geq 7)$ and NICU admission were considered as the binary outcomes. For the continuous outcomes, the multiple linear regression models were used to compare the means between groups after adjusting for age, BMI and number of prior laparotomies. For the outcome variables that were not normally distributed, log-transformation was used to reduce skewness. The overall comparison for these three groups was conducted first and the multiple comparisons using Dunnett's method were conducted to compare epidural and general anesthesia and to compare spinal and general anesthesia. Logistic regression model was used for the binary outcomes after adjusting for age, BMI and number of prior laparotomies. All analyses were performed with SAS statistical software (9.4; SAS Institute, Cary, NC, USA). P-values $<0.05$ were considered to be statistically significant.

\section{Results}

A total of 190 patients were enrolled in the study, however, seven patients were excluded due to the change in the anesthesia status during the course of surgery. 183 patients were, finally, included in the study with 184 total newborns, as one of the mothers delivered twins. Table 1 shows the number of patients under each group and their baseline clinical characteristics. There were no significant differences between the groups in gestational age, body mass index (BMI), number of previous surgeries, or neonatal birth weight. Patients undergoing epidural anesthesia (EA) were significantly younger than the patients undergoing either GA or spinal anesthesia, P 0.006. The majority of patients in each group were

Table 1. Participant characteristics by group+.

\begin{tabular}{ccccc}
\hline Variable & $\begin{array}{c}\text { Epidural anesthesia } \\
(\mathbf{n}=112)\end{array}$ & $\begin{array}{c}\text { Spinal anesthesia } \\
(\mathbf{n}=50)\end{array}$ & $\begin{array}{c}\text { General anesthesia } \\
(\mathbf{n}=\mathbf{2 1})\end{array}$ & P-value $^{*}$ \\
\hline Maternal Age (year) & $28.9(6.91)$ & $32.6(7.56)$ & $31.1(4.92)$ & 0.006 \\
& $39.3(2.04)$ & $38.7(2.67)$ & $36.3(5.50)$ & 0.05 \\
Gestational Age (weeks) & $40.0[38.5-40.4]$ & $39.4[38.2-40.3]$ & $39.0[33.6-40.0]$ & \\
& $32.9(6.60)$ & $33.3(5.62)$ & $31.9(5.14)$ & 0.37 \\
BMI & $32.1[28.8-35.0]$ & $33.2[30.0-37.1]$ & $31.4[28.3-35.7]$ & \\
Number of & & & & \\
Prior Laparotomies & & & & \\
0 & $76(67.9 \%)$ & $32(64.0 \%)$ & $17(80.9 \%)$ & 0.45 \\
1 & $32(28.5 \%)$ & $14(28.0 \%)$ & $3(14.3 \%)$ & \\
2,3 & $4(3.6 \%)$ & $4(8.0 \%)$ & $1(4.8 \%)$ & \\
& $3213(522.9)$ & $3034(748.7)$ & $2641(1026)$ & 0.09 \\
Fetal Weight $^{* *}(\mathrm{~g})$ & $3258[2885-3560]$ & $3203[2770-3445]$ & $2980[2185-3490]$ & \\
\hline
\end{tabular}

+Data provided are Mean (SD) or N (\%). Median (interquartile range: Q1 and Q3) is provided for variables that are not normally distributed. ${ }^{*}$ ANOVA or Kruskal-Wallis Test was used for the continuous variable and fisher's exact test was used for categorical variable. ${ }^{*}$ For Fetal Weight, $\mathrm{N}=21$ in General anesthesia, but there was one missing data. 
having the cesarean section for the first time and the difference in rate of primary cesarean section was insignificant. Table 2 compares the different time intervals between the groups. Fetuses in the GA group were delivered significantly faster when compared to epidural and spinal group separately with a P-value of 0.001. The mean time from Arrival to OR to delivery of the newborn in GA group was 12.7 minutes compared to 27 minutes in epidural group and 32.7 minutes in the spinal group. Time intervals from Time in the OR to incision and Time from incision to delivery of the fetus were also calculated and were significantly shorter in the GA group when compared to spinal and epidural groups, $\mathrm{P}$ $<0.001$.

The estimated blood loss (EBL) was similar between all three groups.

Both arterial and venous umbilical cord mean $\mathrm{pH}$ were comparable in GA, spinal and epidural groups (Table 3). 36\% of newborns had an Apgar score of less than seven at 1 minute in the GA group as compared to $15 \%$ of newborns in the epidural group, and $22 \%$ of newborns in the spinal group, which was not statistically significant.

$27 \%$ of newborns in the GA group continued to have Apgar scores of under seven at five minutes compared to approximately $2 \%$ in the epidural group and $12 \%$ in the spinal group. The statistical significance of these findings could not be calculated due to small number of patients in this group. When comparing the NICU admissions between groups, 54\% of the newborns delivered via epidural

Table 2. Maternal outcomes by group.

\begin{tabular}{|c|c|c|c|c|c|c|c|}
\hline \multirow[t]{2}{*}{ Variable } & \multirow{2}{*}{$\begin{array}{c}\text { Epidural } \\
\text { anesthesia } \\
(\mathrm{n}=112)\end{array}$} & \multirow{2}{*}{$\begin{array}{c}\begin{array}{c}\text { Spinal } \\
\text { anesthesia } \\
(\mathrm{n}=50)\end{array} \\
\mathrm{N}, \text { Mean } \\
(\mathrm{SD})\end{array}$} & \multirow{2}{*}{$\begin{array}{c}\begin{array}{c}\text { General } \\
\text { anesthesia } \\
(\mathrm{n}=21) \\
\mathrm{N}, \text { Mean } \\
(\mathrm{SD})\end{array}\end{array}$} & \multicolumn{2}{|c|}{$\begin{array}{c}\text { Adjusted Mean Difference* } \\
\text { between Epidural and General }\end{array}$} & \multicolumn{2}{|c|}{$\begin{array}{l}\text { Adjusted Mean Difference } \\
\text { between Spinal and Genera }\end{array}$} \\
\hline & & & & $\begin{array}{c}\text { Mean Difference } \\
\text { (SE) }\end{array}$ & $\mathrm{P}$-value & $\begin{array}{c}\text { Mean Difference } \\
\text { (SE) }\end{array}$ & $P$-value \\
\hline $\begin{array}{l}\text { Time from OR arrival to } \\
\text { Delivery (min) }\end{array}$ & $\begin{array}{l}27.02 \\
(9.73)\end{array}$ & $\begin{array}{l}32.76 \\
(9.17)\end{array}$ & $\begin{array}{l}12.76 \\
(7.56)\end{array}$ & $\begin{array}{l}13.57 \\
(2.21)\end{array}$ & $<0.001$ & $\begin{array}{l}19.81 \\
(2.42)\end{array}$ & $<0.001$ \\
\hline $\begin{array}{l}\text { Time from OR arrival to } \\
\text { Incision (min) }\end{array}$ & $\begin{array}{l}16.18 \\
(5.05)\end{array}$ & $\begin{array}{l}23.40 \\
(7.02)\end{array}$ & $\begin{array}{c}9.05 \\
(4.57)\end{array}$ & $\begin{array}{c}7.05 \\
(1.33)\end{array}$ & $<0.001$ & $\begin{array}{l}14.65 \\
(1.46)\end{array}$ & $<0.001$ \\
\hline $\begin{array}{l}\text { Time from Incision to } \\
\text { Delivery (min) }\end{array}$ & $\begin{array}{l}10.84 \\
(6.65)\end{array}$ & $\begin{array}{c}9.36 \\
(5.19)\end{array}$ & $\begin{array}{c}3.71 \\
(4.06)\end{array}$ & $\begin{array}{c}6.51 \\
(1.40)\end{array}$ & $<0.001$ & $\begin{array}{c}5.16 \\
(1.54)\end{array}$ & $<0.001$ \\
\hline $\mathrm{EBL}(\mathrm{ml})$ & $\begin{array}{c}894.6 \\
(142.0)\end{array}$ & $\begin{array}{c}900.0 \\
(269.5)\end{array}$ & $\begin{array}{c}928.6 \\
(164.8)\end{array}$ & $\begin{array}{l}-21.77 \\
(44.4)\end{array}$ & 0.72 & $\begin{array}{r}-40.97 \\
(48.7)\end{array}$ & 0.28 \\
\hline
\end{tabular}

Table 3. Fetal cord blood gases.

\begin{tabular}{|c|c|c|c|c|c|c|c|}
\hline \multirow[t]{2}{*}{ Variable } & \multirow{2}{*}{$\begin{array}{l}\text { Epidural anesthesia } \\
\qquad(\mathrm{n}=112) \\
\mathrm{N}, \text { Mean (SD) }\end{array}$} & \multirow{2}{*}{$\begin{array}{l}\text { Spinal anesthesia } \\
\qquad(\mathrm{n}=50) \\
\mathrm{N}, \text { Mean (SD) }\end{array}$} & \multirow{2}{*}{$\begin{array}{c}\text { General anesthesia } \\
\qquad(\mathrm{n}=21)\end{array}$} & \multicolumn{2}{|c|}{$\begin{array}{c}\text { Adjusted Mean } \\
\text { Difference }{ }^{*} \text { between } \\
\text { Epidural and General }\end{array}$} & \multicolumn{2}{|c|}{$\begin{array}{c}\text { Adjusted Mean } \\
\text { Difference* between } \\
\text { Spinal and General }\end{array}$} \\
\hline & & & & $\begin{array}{c}\text { Mean Difference } \\
\text { (SE) }\end{array}$ & P-value & $\begin{array}{c}\text { Mean Difference } \\
\text { (SE) }\end{array}$ & P-value \\
\hline Arterial Cord $\mathrm{pH}$ & $105,7.22(0.08)$ & $45,7.17(0.11)$ & $17,7.20(0.12)$ & $0.02(0.03)$ & 0.68 & $-0.03(0.03)$ & 0.44 \\
\hline Venous Cord pH & $101,7.26(0.08)$ & $47,7.22(0.11)$ & $21,7.23(0.11)$ & $0.03(0.22)$ & 0.25 & $-0.005(0.02)$ & 0.96 \\
\hline
\end{tabular}


anesthesia were admitted versus 50\% of newborns delivered via spinal anesthesia and $77 \%$ of newborns delivered under GA (Table 4). The majority of the newborns were admitted to NICU for prematurity, sepsis evaluation and respiratory symptoms. Table 5 shows the breakdown of the reasons for the NICU admissions between groups. Two newborns out of twenty two (9\%) in the GA group were evaluated for neonatal hypoxic encephalopathy associated with acute perinatal stress versus none in the other two groups. There was one neonatal mortality in the spinal anesthesia group which was due to undetected severe hydrops fetalis and not related to the perinatal stress.

\section{Discussion}

The choice of the anesthetic technique for Cesarean Section is controversial and multifactorial. In most situations, it is affected by perceived urgency, presence of the working epidural catheter, maternal anatomy and physiology and patient preference.

Table 4. Fetal outcomes by group.

\begin{tabular}{|c|c|c|c|c|c|c|c|}
\hline \multirow[t]{2}{*}{ Variable } & \multirow{2}{*}{$\begin{array}{c}\text { Epidural anesthesia } \\
(\mathrm{n}=112) \\
\mathrm{N}(\%)\end{array}$} & \multirow{2}{*}{$\begin{array}{l}\text { Spinal anesthesia } \\
(\mathrm{n}=50) \\
\mathrm{N}(\%)\end{array}$} & \multirow{2}{*}{$\begin{array}{l}\text { General anesthesia } \\
(n=21) \\
N(\%)\end{array}$} & \multicolumn{2}{|c|}{$\begin{array}{c}\text { Adjusted Odds } \\
\text { Ratio* between } \\
\text { Epidural and General }\end{array}$} & \multicolumn{2}{|c|}{$\begin{array}{c}\text { Adjusted Odds } \\
\text { Ratio* between } \\
\text { Spinal and General }\end{array}$} \\
\hline & & & & OR & $95 \% \mathrm{CI}$ & OR & $95 \% \mathrm{CI}$ \\
\hline \multicolumn{8}{|c|}{ NICU Admission } \\
\hline Yes & $61(54.5 \%)$ & $25(50.0 \%)$ & $17(77.3 \%)$ & 0.38 & $0.13-1.13$ & 0.32 & $0.10-1.05$ \\
\hline No & $51(45.5 \%)$ & $25(50.0 \%)$ & $5(22.7 \%)$ & & & & \\
\hline \multicolumn{8}{|c|}{ Apgar score at $1 \mathrm{~min}$} \\
\hline$\geq 7$ & $95(84.8 \%)$ & $39(78.0 \%)$ & $14(63.4 \%)$ & 3.56 & $1.24-10.2^{\mathrm{a}}$ & 1.89 & $0.61-5.92$ \\
\hline$<7$ & $17(15.2 \%)$ & $11(22.0 \%)$ & $8(36.4 \%)$ & & & & \\
\hline \multicolumn{8}{|c|}{ Apgar score at $5 \mathrm{~min}^{\star *}$} \\
\hline$\geq 7$ & $110(98.2 \%)$ & $44(88.0 \%)$ & $16(72.7 \%)$ & & & & \\
\hline$<7$ & $2(1.8 \%)$ & $6(12.0 \%)$ & $6(27.3 \%)$ & & & & \\
\hline
\end{tabular}

${ }^{*}$ Adjusted for Age, BMI and Number of Prior Laparotomies. ${ }^{\text {PP-value }}<0.05$. ${ }^{*}$ The adjusted model was not done, due to the small sample in " $<7$ " cell.

Table 5. Breakdown of the reasons for NICU admissions by mode of anesthesia.

\begin{tabular}{cccc}
\hline Reason for NICU admission & $\begin{array}{c}\text { Epidural anesthesia } \\
(\mathbf{N}=112)\end{array}$ & $\begin{array}{c}\text { Spinal anesthesia } \\
(\mathbf{N}=50)\end{array}$ & $\begin{array}{c}\text { General anesthesia } \\
(\mathbf{N}=21)\end{array}$ \\
\hline $\begin{array}{c}\text { Maternal fever/newborn sepsis } \\
\text { evaluation }\end{array}$ & $31(27.6 \%)$ & $5(10 \%)$ & $0(0.0 \%)$ \\
Respiratory symptoms/TTN & $17(15 \%)$ & $3(10 \%)$ & $1(4.5 \%)$ \\
Prematurity & $2(1.7 \%)$ & $6(12 \%)$ & $4(18 \%)$ \\
Hypoglycemia/Feeding Issues & $6(5.4 \%)$ & $3(6 \%)$ & $1(4.5 \%)$ \\
Neonatal abstinence monitoring & $2(1.7 \%)$ & $0(0 \%)$ & $0(0 \%)$ \\
Hypoxic encephalopathy & $0(0 \%)$ & $1(2 \%)$ & $2(9 \%)$ \\
Others & $3(2.6 \%)$ & $1(2.1 \%)$ & $1(4.5 \%)$ \\
\hline
\end{tabular}


The American College of Obstetricians and Gynecologists (ACOG) recommends "Decision to Delivery" interval of under 30 minutes for emergency cesarean deliveries. Nonetheless, there is scant literature available regarding the achievability of this threshold in large obstetrical cohorts. "Decision to delivery" interval can be divided into three distinct stages, each one dependent on different factors. The time from decision to entering the OR depends on prompt recognition of abnormal fetal heart rate tracings, team availability and team training. The time from entering the OR to incision depends on the choice of anesthesia, time to induction of anesthesia and expeditious time-out. The time from incision to delivery is related to the expertise of the surgical team. Improvement of each of these elements requires different tools and strategies, as rapid delivery can only be assured when all required components are in place.

The choice of anesthetic is between Neuraxial (including Spinal and Epidural) and General Anesthesia (GA). Since the 1980s, GA has been progressively less utilized due to perceived safety issues and improvement of maternal and fetal outcomes in patients under neuraxial anesthesia. Meanwhile, recent studies have shown safer and more positive outcomes in GA cases, as well as shorter interval to induction of anesthesia and high patient satisfaction rate [6]. Patient satisfaction with different anesthesia modalities for CS was not part of this study and will be addressed in further research.

In our study, the majority of patients (88\%) who underwent CS for nonreassuring fetal tracing received regional anesthesia. Epidural catheter was placed earlier during labor and activated for CS in 69\%, and 31\% received primary spinal anesthesia. $11 \%$ received GA as the primary anesthetic of choice. Of note, 7 (4\%) of patients were converted from regional technique to GA due to inadequate level of surgical anesthesia, which is an acceptable rate of conversion to GA in published literature [7]. We believe those numbers reflect team to focus on early epidural placement and high level of interdisciplinary communication.

Our study demonstrated significantly shorter time from entrance to the OR to delivery interval in the general anesthesia group, compared to both spinal and epidural anesthesia: 12 minutes for GA, 27 minutes of epidural and 32 minutes for spinal anesthesia respectively. The difference in epidural versus spinal group in the OR to incision interval can be attributed to the patient positioning and the time required for spinal administration.

All cases in GA group had Category 1 indications for cesarean section (Lifethreatening indications: e.g. cord prolapse with fetal bradycardia). The cases in regional anesthesia group were category 1 (emergency) and category 2 (urgent) combined. As one can see from shorter time from incision to delivery in the general anesthesia group, there was higher pressure to deliver Category 1 cases more expeditiously, as would be expected due to life-threatening indications. The role of GA will always be secondary to regional due to maternal safety concerns. On the other hand, in cases of the true obstetrical emergencies, when working epidural is not available, GA should be considered and utilized. We believe that the reluctance of anesthesia providers to administer GA for urgent and 
emergent CS is primarily based on the previous studies, prior to introduction of new airway devices and video laryngoscopy airway management in anesthesia cases in labor and delivery settings. As our data demonstrate, approximately 1:10 of urgent and emergent deliveries require GA as the most appropriate method of anesthesia. Therefore, the anesthesia department continues to face the challenge of maintaining vigilance and training to be prepared for such rare events. Team training exercises and debriefs appear to improve team performance in these life threatening emergencies [8] [9]. It is also important to keep in mind that cord gas values were similar between the groups, as well as perioperative blood loss, which correlates with other publications [10].

The limitations of the current study include the retrospective design, small number of category 1 cesarean sections requiring general anesthesia and grouping of emergency and urgent cesarean sections together. These limitations and confounding apply to most studies on general anesthesia in obstetrics, as there are ethical barriers on performing prospective studies [11].

The seamless performance of emergency cesarean section requires adequate staffing, immediate availability of surgeon, anesthesia and nursing staff and performance as a well-functioning team. Potential solutions to these obstacles include multidisciplinary rounds, drills and frequent equipment checks. The follow-up study could assess the effectiveness of those interventions [11].

\section{Conclusion}

In conclusion, our data demonstrated that general anesthesia for emergency cesarean section was not associated with negative maternal outcomes, resulted in shorter times to delivery and associated with lower, albeit not statistically significant, Apgar scores and higher NICU admissions.

\section{Conflicts of Interest}

The authors declare no conflicts of interest regarding the publication of this paper.

\section{References}

[1] Apfelbaum, J.L., Hawkins, J.L., Agarkar, M., et al. (2016) Practice Guidelines for Obstetric Anesthesia: An Updated Report by the American Society of Anesthesiologists Task Force on Obstetric Anesthesia and the Society for Obstetric Anesthesia and Perinatology. Anesthesiology, 124, 270-300. https://doi.org/10.1097/ALN.0000000000000935

[2] Juang, J., Gabriel, R.A., Dutton, R.P., Palanisamy, A. and Urman, R.D. (2017) Choice of Anesthesia for Cesarean Delivery: An Analysis of the National Anesthesia Clinical Outcomes Registry. Anesthesia Analgesia, 124, 1914-1917. https://doi.org/10.1213/ANE.0000000000001677

[3] Tolcher, M.C., Johnson, R.L., El-Nashar, S.A. and West, C.P. (2014) Decision-to-Incision Time and Neonatal Outcomes: A Systematic Review and $\mathrm{Me}$ ta-Analysis. Obstetrics \& Gynecology, 123, 536-548. https://doi.org/10.1097/AOG.0000000000000132 
[4] Kathirgamanathan, A., Douglas, M.J., Tyler, J., Saran, S., Gunka, V., Preston, R. and Kliffer, P. (2013) Speed of Spinal vs. General Anaesthesia for Category-1 Caesarean Section: A Simulation and Clinical Observation-Based Study. Anaesthesia, 68, 753-759. https://doi.org/10.1111/anae.12290

[5] Plante, L. and Gaiser, R. (2017) Practice Bulletin No. 177 Summary: Obstetric Analgesia and Anesthesia. Obstetrics Gynecology, 129, 766-768.

https://doi.org/10.1097/AOG.0000000000002009

[6] Afolabi, B.B. and Lesi, F.E. (2012) Regional versus General Anaesthesia for Caesarean Section. Cochrane Database of Systematic Reviews, 17, CD004350. https://doi.org/10.1002/14651858.CD004350.pub3

[7] Rafi, M.A., Arfeen, Z. and Misra, U. (2010) Conversion of Regional to General Anaesthesia at Caesarean Section: Increasing the Use of Regional Anaesthesia through Continuous Prospective Audit. International Journal of Obstetric Anesthesia, 19, 179-182. https://doi.org/10.1016/j.ijoa.2009.08.008

[8] Weiner, E., Bar, J., Fainstein, N., Ben-Haroush, A., Sadan, O., Golan, A. and Kovo, M. (2014) The Effect of a Program to Shorten the Decision-to-Delivery Interval for Emergent Cesarean Section on Maternal and Neonatal Outcome. American Journal of Obstetrics Gynecology, 210, 224.e1-224.e6.

https://doi.org/10.1016/j.ajog.2014.01.007

[9] Russell, T., Khan, S., Elman, J., Katznelson, R. and Cooper, R.M. (2012) Measurement of Forces Applied during Macintosh Direct Laryngoscopy Compared with GlideScope ${ }^{\circledast}$ Videolaryngoscopy. Anaesthesia, 67, 626-631. https://doi.org/10.1111/j.1365-2044.2012.07087.x

[10] Heesen, M., Hofmann, T., Klöhr, S., Rossaint, R., van de Velde, M., Deprest, J. and Straube, S. (2013) Is General Anaesthesia for Caesarean Section Associated with Postpartum Haemorrhage? Systematic Review and Meta-Analysis. Acta Anaesthesiologica Scandinavica, 57, 1092-1102. https://doi.org/10.1111/aas.12178

[11] Butwick, A.J. and Palanisamy, A. (2018) Mode of Anaesthesia for Caesarean Delivery and Maternal Morbidity: Can We Overcome Confounding by Indication? British Journal of Anaesthesia, 120, 621-623. https://doi.org/10.1016/j.bja.2018.01.002 